\title{
PENINGKATAN PARIWISATA MELALUI PUBLIC PRIVATE PARTNERSHIP DI DESA WARNASARI KECAMATAN PANGALENGAN KABUPATEN BANDUNG
}

Ine Mariane, Soleh Suryadi, Taqwaty Firdausijah, Rizki Ilhami

Prodi Administrasi Negara, Fakultas Ilmu Sosial dan Ilmu Politik, Universitas Pasundan ine.mariane@unpas.ac.id, soleh.suryadi@unpas.ac.id, taqwaty.firdausijah@unpas.ac.id,

\section{rizki.ilhami@unpas.ac.id}

\section{ABSTRAK}

Masalah utama yang dihadapi oleh Karang Taruna sebagai pelaku usaha wisata di Desa Warnasari, salah satunya yaitu belum terbentuknya komitmen untuk membuat kemitraan dalam perencanaan di daerahnya, karena kurangnya sumber daya dan modal yang dimiliki. Tujuan dari pengabdian pada masyarakat ini adalah untuk mendidik pelaku usaha terkait dengan potensi agrowisata yang ada dengan sumber daya yang dibutuhkan untuk membangun kemitraan melalui kemitraan masyarakat, pemerintah, dan dunia industri/usaha yang diperlukan untuk mengembangkan potensi pariwisata yang ada. Metodologi pelaksanaan pengabdian pada masyarakat dibagi menjadi 3 (tiga) yaitu observasi, pelatihan, dan simulasi. Hasil pengabdian pada masyarakat di desa Warnasari, Kecamatan Pangalengan, Kabupaten Bandung, adalah membangun kemitraan masyarakat, pemerintah, dan dunia industri/usaha sehingga membentuk MOU juga mendapatkan kemampuan mengelola pariwisata di desa Warnasari, Kecamatan Pangalengan, Kabupaten Bandung.

Dampak dari pengabdian pada masyarakat yaitumembantu karang taruna sebagai pelaku usaha pariwisata dan aparat desa dalam mengembangkan potensi yang ada melalui kemitraan masyarakat, pemerintah, dan dunia industri/usaha yang ada sehingga terbentuk MOU. Manfaat dari pengabdian pada masyarakat adalah tercapainya kesejahteraan masyarakat Warnasari. Desa, Kecamatan Pangalengan, Kabupaten Bandung, dengan meningkatnya pariwisata di daerah tersebut.

Kata kunci: Kemitraan masyarakat, pemerintah, dan dunia industri/usaha, Peningkatan Pariwisata.

\begin{abstract}
The main problem responded by partners is Karang Taruna as a business effort in Warnasari, one of which has not yet formed a commitment to make partnerships in planning in its area, because of the lack of resources and capital owned.The purpose of this community service program is to educate business actors related to the potential of existing agrotourism with the resources needed to build partnerships through private-public partnerships needed to develop existing tourism potential.The methodology of implementation in community service is divided into 3 (three) steps : observation, training, and simulation. The result of community service activities in the village of Warnasari, Pangalengan Sub-district, Bandung Regency, was to build a public private partnership so that forming an MOU also gained the ability to manage tourism in the village of Warnasari, Pangalengan District, Bandung Regency.

The impact of community service activities is the assistance of youth organizations as an aid to businesses and village apparatus in developing existing potential through private public partnerships developed by the MOU.The benefit of community service activities is the achievement of the welfare of the people of Warnasari Village, Pangalengan District, Bandung Regency, with tourism support in the area.
\end{abstract}

Keywords : Public Private Partnership, Increased Tourism. 


\section{PENDAHULUAN}

Kecamatan Pangalengan terletak di bagian selatan Ibu Kota Kabupaten Bandung yaitu Soreang yang berjarak 23 kilometer dan berjarak 51 kilometer dari pusat Kota Bandung. Dibatasi oleh Kecamatan Cimaung di sebelah utara, Kecamatan Talegong Kabupaten Garut di sebelah selatan, Kecamatan Pasirjambu di sebelah barat, Kecamatan Kertasari dan Kecamatan Pacet di sebelah timur. Kecamatan Pangalengan terbagi menjadi 13 desa yaitu Lamajang, Margaluyu, Margamekar, Margamukti, Margamulya, Pangalengan, Pulosari, Sukaluru, Sukamanah, Tribaktimulya, Wanasuka, Warnasari, dan Banjarsari.

Pangalengan merupakan salah satu kecamatan di Kabupaten Bandung yang merupakan daerah sentra pertanian. Sektor pertanian menyumbang terbesar dari total produk domestik regional. Bruto Kecamatan Pangalengan bahkan ke tingkat Kabupaten, penyumbang ketiga terbesar setelah sektor industri (tanpa migas), pertambangan dan penggalian (minyak dan gas bumi). Melihat potensi yang ada maka sektor pertanian merupakan sektor yang patut mendapat perhatian lebih, baik dari pihak pemerintah daerah maupun masyarakat pertanian itu sendiri.

Beberapa jenis tanaman pangan yang diusahakan di Kecamatan Pangalengan, antara lain padi, jagung, ubi kayu, ubi jalar, kacang panjang dan kacang merah. Produksi dan luas tanaman pangan terbanyak adalah tanaman padi sawah sebanyak 6.267 ton, dengan luas panen $1.481 \mathrm{Ha}$ sedangkan tertinggi kedua adalah jagung sebanyak 5.886 ton, luas panen $393 \mathrm{Ha}$. Hal ini mempengaruhi tingkat produktivitas tanaman padi menjadi 42,32 kw/Ha ditahun 2017 ada kenaikkan ditahun sebelumnya.

Padi dan palawija produksinya masih berada di peringkat bawah. Keadaan ini dapat dipahami karena luas areal untuk tanaman padi cukup kecil jika dibandingkan dengan luas areal yang ditanami tanaman holtikuktura yaitu seluas 2159,50 Ha untuk tanaman kentang dengan produktifitas 42.889 ton, tanaman kol $1.214,60 \mathrm{Ha}$ produksi $30.634,00$ ton, tanaman cabe 345,69 Ha produksi 4.094 ton, tanaman bawang merah 374,83 Ha produksi 20.358 ton, tanaman wortel 806,00 Ha produksi 18.520,80 ton, tanaman tomat 665,85 Ha produksi 15.494 ton, tanaman labu siam 12,00 Ha produksi $55.650,50$ ton, dan tanaman sawi 791,00 Ha produksi 18.054 ton sedangkan tanaman pangan dan holtikultura lainnya berkisar antara 1 hingga 56 Ha saja. Untuk semua tanaman di tahun 2017 mengalami penaikan dan penurunan di tahun sebelumnya disebabkan yang utama faktor cuaca yang tidak menentu.

Primadona di Kecamatan Pangalengan adalahTanaman holtikultura dibandingkan dengan tanaman pangan lainnya, tanaman holtikultura memiliki tanaman unggulan yaitu sepert kentang, kol, petsai/sawi, wortel, tomat, labu siam, bawang merah, cabe serta diikuti tanaman buah- buahan yaituh jeruk, alpukat dan pisang. Untuk Tanaman perkebunan seperti, teh dan kopi, strawberi yang juga usahakan di Kecamatan Pangalengan.

Peternakan menjadi unggulan di daerah ini. Berdasarkan jenis peternakan dibedakan atas ternak besar, ternak kecil dan ternak unggas. Jenis ternak besar yang cukup dominan di Kecamatan Pangalengan adalah sapi perah sebanyak 16.001 ekor, kerbau 20 ekor dan kuda sebanyak 8 ekor dan Sapi Potong 224 ekor. Sementara ternak kecil yang cukup dominan adalah domba sebanyak

7.011 ekor kemudian kambing sebanyak 428 ekor. Sedangkan jenis ternak unggas terbesar adalah ternak ayam, dimana pada tahun 2017 mencapai 39.701 ekor ( ayam kampung ) disusul itik sebanyak 2.809 ekor dan jenis ayam broiler 1.062.824 ekor yang di usahakan di Kecamatan Pangalengan.

Letaknya yang berada di daerah pegunungan menjadikan Kecamatan Pangalengan hanya memproduksi ikan hasil budidaya air tawar. Jumlah pembudidaya ikan dibedakan menurut keramba dan empang/kolam yang paling banyak di usahakan yaitu empang/kolam sebanyak kurang lebih 557 unit.

Tanaman perkebunan, yang diusahakan dan yang utama adalah teh dan kopi. Tanaman kopi yang diusahakan oleh masyarakat 912,10 Ha, pihak swasta 360,00 Ha. Tanaman Kopi meningkat di tahun sebelumnnya dan untuk tanaman Teh yang di kelola oleh masyarakat tercatat 328,97 Ha , pihak swasta / BUMN sebesar 5.682,02 Ha ini tanamnya ada di lahan adat, Swasta ada juga di lahan milik pemerintah/lahan kehutanan.

Pangalengan selain menjadi daerah pertanian dan perkebunan di Jawa Barat juga sangat popular sebagai produsen dan penghasil susu sapi segar terbaik di daerah Bandung juga dikenal sebagai daerah wisata alam Bandung yang sangat mempesona dengan suhu udara 
yang sangat dingin bisa dirasakan pada malam hari. Potensi pariwisata pangalengan yang merupakan daya tarik wisata antara lain :

1. Situ Cileunca.

2. Pemandian air panas Cibolang

3. Situ Cisanti

4. Situs Rumah Adat Cikondang

5. Kebon The Malabar

6. Curug Panganten

7. Sungai Palayangan

8. Gunung Malabar

9. Gunung Nini

Desa Warnasari merupakan bagian dari Kecamatan Pangalengan Kabupaten Bandung Provinsi Jawa Barat. Desa Wamasari memiliki luas wilayah 2.354,119 Hektar, terletak pada ketinggian $\pm 1442 \mathrm{mdpl}$ dan memiliki suhu udara rata-rata $12^{\circ} \mathrm{C}-25^{\circ} \mathrm{C}$. Batas wilayah Desa Wamasari adalah : Sebelah utara : Desa Pulosari Sebelah timur : Desa Pulosari Sebelah selatan : Desa Margaluyu Sebelah barat :Kecamatan Pasir Jambu 64 Desa Wamasari memiliki 17 Rukun Warga dan 17 bmpung yaitu Barn Taraje, Ciawitali, Cibeunying, Cibunihayu, Cidurian, Cipangisikan, Citiis, Kapas, Kiaracondong, Munjul, Neglasari, Padahurip, Palayangan, Parabon, Pasir Ucing, Singkur, dan Wanasari.

Lokasi TPK Warnasari berada didepan Jalan utama Desa Warnasari di RW 02 Kampung Warnasari berjarak \pm 300 meter ke sebelah barat dari kantor Desa Warnasari. Penempatan TPK Warnasari yang terletak di lokasi pusat desa mudah dijangkau oleh para peternak di daerah utara dan selatan serta memudahkan truk untuk mendistribusikan susu yang dikumpulkan petemak ke lokasi industri pengolahan susu (PT. Frisian Flag).

Berdasarkan gambaran di atas, Desa Warnasari mempunyai potensi yang besar sebagai daerah penghasil produk pertanian yang dapat dikembangkan sebagai agroindustri dan agrowisata. Selain padi dan palawija, yang merupakan hasil pertanian secara umum, Desa Warnasari juga dikenal sebagai penghasil beberapa produk pertanian holtikultura. Dalam upaya pengembangan usaha tani di Desa Warnasari, pada dasarnya diperlukan keterlibatan pihak masyarakat, pengusaha (dunia industri), dan pemerintah yang terdiri dari penghasil produk, pengolah, pedagang, distributor, importir dan eksportir. Pelakupelaku ini merupakan komponen atau subsistem yang membentuk sebuah sistem agribisnis. Sistem tersebut, di tahun-tahun mendatang diharapkan agar lebih berfungsi secara optimal demi mewujudkan tingkat kesejahteraan masyarakat. Oleh karena itu, pemerintah Desa Warnasari melalui program pembinaan dan pemberdayaan masyarakat akan selalu berupaya agar semua subsistem itu lebih siap dalam menjalankan perannya secara profesional.

Panorama alam yang ditawarkan oleh Situ Cileunca sangat indah serta hijaunya perkebunan teh Malabar dan tiga gunung yang mengelilingi yaitu gunung Malabar, gunung Windu, serta gunung Wayang menambah keindahan Situ Cileunca. Selain itu, ada beberapa tempat wisata di Desa Warnasari yang sudah dikenal oleh wisatawan domestik maupun wisatawan internasional seperti situ cileunca, rafting, wisata kebun teh, pemandian air panas cibolang, dan masih banyak potensi lahan yang bisa di jadikan tempat wisata.

Berdasarkan analisis situasi diatas, dalam kegiatan pengabdian masyarakat ini pelaku usaha di bidang pariwisata dalam mengembangkan potensi agrowisata di desa Warnasari Kabupaten Bandung menemui beberapa masalah diantaranya yaitu aspekaspek sebagai berikut :

1. Karang taruna sebagai pelaku usaha wisata kurang mempunyai keahlian dalam mengelola Potensi pariwisata yang ada, diantaranya keahlian dalam menggali dan mempromosikan potensi daerahnya

2. Sumber Daya Alam, Desa Warnasari memiliki objek wisata yang belum menonjolkan ciri khas wilayah utama sebagai destinasi wisata dengan ciri pemandangan yang indah, khas hasil bumi, kebudayaan, dan kerajinan rakyat.

3. Permodalan, karang taruna sebagai pelaku usaha pariwisata belum mendapat bantuan dari perbankan maupun Investor, baru sebatas uang pribadi.

4. Kemitraan, aparat desa dan karang taruna dalam mengelola potensi wisata yang ada belum menjalin kerjasama dengan berbagai pihak khususnya dengan investor.

Masalah utama yang dihadapi oleh mitra yaitu karang taruna sebagai pelaku usaha pariwisata di Desa Warnasari Kabupaten Bandung salah satunya adalah belum terbentuknya komitmen untuk melakukan kemitraan dalam mengelola pariwisata yang ada didaerahnya, dikarenakan minimnya sumberdaya dan permodalan yang dimiliki.

Tujuan dari program pengabdian masyarakat ini adalah untuk mengedukasi para pelaku usaha pariwisata didalam mengelola potensi agrowisata yang ada dengan menyiapkan 
sumber- sumber yang diperlukan untuk membangun kemitraan melalui public private partnership yang dibutuhkan untuk mengembangkan potensi pariwisata yang ada.

Target yang diharapkan mitra dari kegiatan pengabdian pada masyarakat yaitu karang taruna sebagai pelaku usaha pariwisata di desa Warnasari Kabupaten Bandung mampu membangun/menjalin public private partnership (kerjasama kemitraan) dengan berbagai pihak (pemerintah, masyarakat, pengusaha, dan akademisi) dalam mengelola potensi pariwisata agar bisa berkembang.

Luaran yang diharapkan yaitu terbentuknya public private partnership diantara aparatur desa, karang taruna sebagai pelaku usaha pariwisata, dan pengusaha di desa Warnasari Kab. Bandung (yaitu dengan pendekatan public private partnership) sehingga dapat menghasilkan MOU.

\section{METODE DAN RENCANA PELAKSANAAN}

Metodologi pelaksanaan dalam pengabdian pada masyarakat ini dilakukan melalui kegiatan pelatihan. Pelatihan adalah proses belajar bersama yang dilakukan oleh beberapa orang untuk memahami atau menguasai sesuatu pengetahuan atau keahlian tertentu. Ahsanul Minan ( 2003 : 3). Adapun metode yang dilakukan menurut T Hani Handoko (2012 : 115) adalah dalam bentuk Kuliah yaitu merupakan metode tradisional dengan kemampuan penyampaian informasi, banyak peserta dan biaya relatif murah. Metode ini cenderung lebih tergantung pada komunikasi, bukan modeling. Berupa ceramah yang disampaikan secara lisan. Metode ini harus dikombinasikan dengan metode lainnya seperti diskusi dan tanya jawab karena peserta cenderung pasif disebabkan adanya komunikasi satu arah saja.

Kegiatan ini dibagi menjadi 3 (tiga) tahap yaitu tahap awal (observasi), tahap kedua (pelaksanaan melalui pelatihan) dan tahap akhir (monitoring dengan metode simulasi).

\section{HASIL DAN PEMBAHASAN}

Hasil kegiatan pengabdian masyarakat di desa Warnasari Kecamatan Pangalengan Kabupaten Bandung yaitu membangun public private partnership sehingga terbentuk MOU juga memperoleh kemampuan mengelola pariwisata dalam meningkatkan pariwisata di desa Warnasari Kecamatan Pangalengan Kabupaten Bandung, yang mana pelaksanaannya adalah sebagai berikut. a. Persiapan

Pada tahap awal dilaksanakan observasi, dan wawancara secara langsung dengan mitra, hal ini bertujuan untuk mengetahui gambaran kondisi mitra dan untuk mengetahui permasalahan/kendala yang dihadapi oleh karang taruna sebagai pelaku usaha pariwisata juga aparatur desa yang berperan sebagai fasilitator dalam pembangunan pariwisata, sehingga dapat diketahui aktifitas apa yang harus dilakukan atau menjadi Action Plan dalam pengabdian masyrakat yang meliputi mendata peserta yang akan mengikuti pelatihan dan kesiapan instruktur sebagai bagian dari tim pengabdian, menyusun jadwal kegiatan, menyusun materi dan mempersiapkan tempat untuk kegiatan berlangsung.

b. Pelaksanaan

Tahap kedua adalah tahap pelaksanaan berupa: Pelatihan bagaimana membuat/menjalin public private partnership dengan berbagai pihak kemudian dilanjutkan dengan pelatihan bagaimana mengelola potensi pariwisata yang meliputi :

Tahap yang terakhir adalah tahap monitoring. Pada tahap terakhir ini, tim pengabdian masyarakat melakukan simulasi kepada karang taruna sebagai pelaku usaha wisata dan juga aparatur desa tentang bagaimana membentuk kerjasama dengan perusahaan Frisian Flag yang ada di wilayah tersebut sehingga hambatan-hambatan dan kesulitan yang dihadapi dapat ditangani melalui public private partnership yang diharapkan dapat menjadi MOU diantara ketiga pihak terkait.

\section{DAMPAK DAN MANFAAT KEGIATAN}

Dampak dari kegiatan pengabdian masyarakat yaitu membantu karang taruna sebagai pelaku usaha pariwisata dan aparatur desa dalam mengembangkan potensi yang ada melalui pendekatan public private partnership sehingga terbentuk MOU yang di harapkan dapat menangani hambatan-hambatan yang dihadapi dalam pengelolaan pariwisata di Desa Warnasari, Kecamatan Pangalengan, Kabupaten Bandung.

Manfaat kegiatan pengabdian pada masyarakat adalah tercapainya kesejahteraan masyarakat desa Warnasari Kecamatan Pangalengan Kabupaten Bandung dengan meningkatnya pariwisata di daerah tersebut. 


\section{TABEL DAN GAMBAR}

Pembahasan keadaan umum daerah pengabdian yang akan di uraikan berasal dari data profil Desa Warnasari, Kecamatan Pangalengan, Kabupaten Bandung.

Tabel 1

Tata Guna Lahan Desa Warnasari

\begin{tabular}{|l|l|r|r|}
\hline No. & $\begin{array}{c}\text { Kegunaan } \\
\text { Lahan }\end{array}$ & $\begin{array}{c}\text { Luas } \\
\text { Lahan }(\mathrm{Ha})\end{array}$ & $\begin{array}{c}\text { Jumla } \\
\mathrm{h}(\%)\end{array}$ \\
\hline 1. & Pemukiman & 51,003 & 2,17 \\
\hline 2. & Perkebunan & 314,610 & 13,37 \\
\hline 3. & $\begin{array}{l}\text { Fasilitas } \\
\text { Umum }\end{array}$ & 198,610 & 8,44 \\
\hline 4. & Ladang/Tegal & 437,561 & 18,58 \\
\hline 5. & Perhutanan & 1352,335 & 57,44 \\
\hline \multicolumn{2}{|c|}{ Total Luas Lahan } & 2354,119 & 100,00 \\
\hline
\end{tabular}

Tabel 2

Mata Pencaharian Penduduk Desa Wamasari

\begin{tabular}{|c|c|c|c|c|}
\hline No. & $\begin{array}{c}\text { Jenis } \\
\text { Pekerjaan }\end{array}$ & \multicolumn{2}{|c|}{ Jenis Kelamin } & Jumlah \\
\hline 1. & Petani & 421 & 97 & 15,21 \\
\hline 2. & Buruh Tani & 867 & 681 & 45,40 \\
\hline 3. & $\begin{array}{c}\text { Pegawai } \\
\text { Negri Sipil }\end{array}$ & 12 & 14 & 0,77 \\
\hline 4. & $\begin{array}{c}\text { Pengrajin } \\
\text { Industri } \\
\text { Rumah } \\
\text { Tangga }\end{array}$ & 19 & 43 & 1,81 \\
\hline 5. & $\begin{array}{c}\text { Pedagang } \\
\text { Keliling }\end{array}$ & 228 & 129 & 10,47 \\
\hline 6. & Peternak & 394 & 21 & 12,17 \\
\hline 7. & Lainnya & 222 & 261 & 14,17 \\
\hline & Total & 2163 & 1248 & 100,00 \\
\hline
\end{tabular}

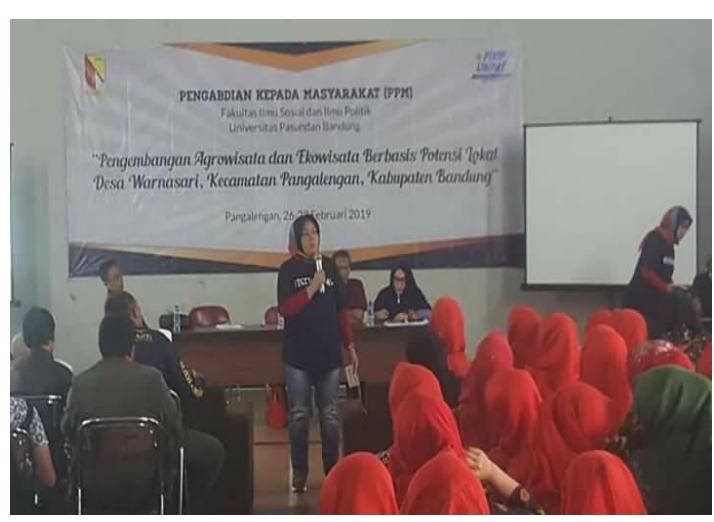

Gambar 1

Kegiatan pemberdayaan masyarakat di Desa Warnasari, Kecamatan Pangalengan, Kabupaten Bandung

\section{KESIMPULAN DAN SARAN}

Kegiatan pengabdian pada masyarakat di Desa Warnasari Kecamatan Pangalengan Kabupaten Bandung ialah meningkatkan kemampuan karang taruna sebagai pelaku usaha dan aparatur desa sebagai fasilitator dalam mengelola dan meningkatkan potensi wisata yang ada.

Pendekatan public private partnership dapat meningkatkan kerjasama (MOU) diantara berbagai pihak yang berkepentingan, dimana aparatur desa harus bisa memfasilitasi arah kebijakan pariwisata, karang taruna sebagai pelaku usaha wisata dengan kemampuan mengelola pariwisata bisa menggali potensi wisata yang memiliki ciri khas wilayahnya sehingga dapat menarik investor dalam hal ini perusahaan frisan flag untuk bisa terlibat dalam investasi pariwisata, sehingga tercipta sinergitas didalam peningkatan pariwisata di desa Warnasari Kecamatan Pangalengan Kabupaten Bandung.

Saran, sebaiknya peningkatan pariwisata di desa Warnasari Kecamatan Pangalengan Kabupaten Bandung dilakukan dengan adanya kesepahaman diantara pelaku pariwisata yaitu : aparatur desa, karang taruna dan perusahaan frisian flag.

\section{DAFTAR REFERENSI}

Handoko T. Hani, 2012, Manajemen Personalia dan Sumberdaya Manusia, Edisi II, Cetakan Keempat Belas, Penerbit BPFE, Yogyakarta

Mariane Ine, 2018. Azas-Azas Manajemen , Kencana Utama, Bandung 
2018. Jejaring kebijakan, (Assisting the Political Parties for Capacity

Pandiva Buku, Yogyakarta

Minan Ahsanul, 2003, Modul Pelatihan

Technology Of Participatory Modul tentang

Tehnik Memfasilitasi Pelatihan, Seminar, dan Diskusi. Disusun oleh Tim APPROACH
Building)

Suryadi Soleh, 2014. Administrasi Publik dan Otonomi Daerah, Prisma Press, Bandung 